\title{
Plano de cargos, carreira e remuneração do magistério público municipal de Boa Vista (RR): uma análise da valorização e do estímulo ao trabalho docente ${ }^{12}$
}

\author{
Career plan of municipal teachers of Boa Vista (RR): \\ analysis of the enhancement and stimulus ofteaching work
}

\section{Maria Angélica Pedra Minhoto ${ }^{3}$ Célia Maria Benedicto Giglio ${ }^{4}$}

\section{Resumo}

O objetivo do deste artigo é analisar a estrutura da carreira do magistério público municipal de Boa Vista (RR), por meio da lei que instituiu o atual Plano de Cargos, Carreira e Remuneração, com o intuito de contribuir para revelar a diversidade de realização das políticas de valorização docente. A análise mostrou que, apesar do movimento ascendente na carreira estar condicionado a uma avaliação de desempenho que pouco contribui para valorizar o magistério, a situação salarial e trabalhista dos docentes boa-vistenses constitui-se como fator de estímulo para os futuros postulantes à profissão no município.

Palavras chave: carreira do magistério; valorização profissional; remuneração docente.

\begin{abstract}
This paper aims at analyzing the structure of the Career Plan of Municipal Teachers of Boa Vista (RR). It takes into account the prescriptions of the law which established the current Career Plan in order to reveal the diversity of achievement of the Teacher Enhancement's Policy. The analysis showed that the salary and the labor situation of teachers are factors of stimulus for future applicants to the profession in that city, despite of the upward movement in their careers has been conditioned to a performance evaluation that does little to enhance the teaching.
\end{abstract}

Keywords: teachers' career, professional

development, teachers pay

\begin{abstract}
1 Este artigo é parte da pesquisa nacional "Remuneração de professores de escolas públicas da educação básica: configurações, impactos, impasses e perspectivas", financiada segundo o Edital $n^{0}$. 001/2008 da CAPES / INEP / SECAD - Observatório da Educação, realizada junto ao Centro de Estudos e Pesquisas em Políticas Públicas de Educação (CEPPPE) da Faculdade de Educação da Universidade de São Paulo, coordenada nacionalmente pelo Prof. Dr. Rubens Barbosa de Camargo, sendo desenvolvida em 12 (doze) estados (São Paulo, Paraná, Rio Grande do Sul, Santa Catarina, Mato Grosso do Sul, Mato Grosso, Paraíba, Piauí, Roraima, Pará, Minas Gerais e Rio Grande do Norte), envolvendo nove (nove) programas de Pós-Graduação em Educação (USP, UFPA, UFPI, UFPB, UFRN, UEMG, UFMS, UFPR, UNISUL), contando ainda com 04 (quatro) grupos colaboradores de pesquisa (USP-RP, UNIFESP, UFMT, UFRGS).

2 Embora a responsabilidade pelo artigo seja da autora, o texto contou com contribuições da equipe de pesquisadores de São Paulo: Prof. Dr. Rubens Barbosa de Camargo (USP), Profa. Dra. Lisete Regina Gomes Arelaro (USP), Profa. Dra. Márcia Aparecida Jacomini (UNIFESP), Ms. Adriana Inácio Yanaguita (Doutoranda-UNESP/Marília), Ms Katia Aparecida Santos (Auxiliar de Pesquisa - Professora da rede municipal/SP), Nilson Alves de Souza (Mestando - USP), Ana Paula Santiago Nascimento (Mestranda - USP), Flávio Pinto Silva (IC-USP, até outubro/2010), Renata Rodrigues de Amorim Medina (IC-USP, desde julho/2010) e Claudia Alves Pereira (Auxiliar de Pesquisa - Professora rede estadual/SP, após outubro/2010).
\end{abstract}

3 Doutora em Educação (PUC-SP). Professora da Universidade Federal de São Paulo. mminhoto@unifesp.br.

4 Doutora em Educação e professora da UNIFESP (Campus Guarulhos), e-mail celiagiglio.edu@bol.com.br 


\section{Introdução}

O presente trabalho pretende analisar o atual Plano de Cargos, Carreira e Remuneração (PCCR) do magistério público da cidade de Boa Vista, capital de Roraima, instituído recentemente pela Lei $n^{\circ} 1.145$, de 20/05/2009. O artigo estuda a estrutura da carreira dos professores boa-vistenses nointuito de contribuir para revelar a diversidade de realização das políticas que declaram valorizar os docentes e melhorar os mecanismos de financiamento da educação básica. Antes de expor o produto das análises do PCCR, vale destacar algumas características específicas de Boa Vista e do atendimento educacional como forma de contextualizar os resultados do estudo em tela.

\section{Boa Vista e o Sistema Municipal de Educação}

O município de Boa Vista está situado na Região Norte do país, é a capital de Roraima, antigo Território Federal que ganha status de Estado em 1988, com a Constituição Federal. Segundo informações disponíveis no sítio da Prefeitura de Boa Vista ${ }^{5}$, a partir da década de 1980 começa a haver forte expansão demográfica na cidade com processos de imigração motivados pelo garimpo, com um rápido e intenso processo de urbanização. Além do extrativismo, a economia da cidade assenta-se principalmente no setor de serviços e na agropecuária.

O crescimento demográfico trouxe para os governos do estado e do município diversas demandas por serviços públicos, entre os quais a educação, o que tem exigido a ampliação de oferta de vagas nas escolas e a contratação de novos docentes. De acordo com Souza, Santos e Souza (2008), Boa Vista concentra as principais atividades produtivas de Roraima e é o principal núcleo urbano do estado. O dinamismo da cidade depende fortemente do setor público, que opera como 0 principal investidor e empregador. 0 PIB desse município tem sido alavancado pelo setor terciário, graças à forte participação do setor público (SOUZA, SANTOS e SOUZA, 2008, p. 89).

A cidade está, atualmente, em fase de médio desenvolvimento humano, segundo os autores,

5 Informações obtidas em http://www.boavista.rr.gov.br/conheca. php, acesso em 29/10/2010. que mostram o fator educação como decisivo para o crescimento do Índice de Desenvolvimento Humano - Municipal (IDH-M), entre 1991 e 2000. Infelizmente, não encontram o mesmo resultado quando analisaram a contribuição do fator renda, revelando participação mínima na melhoria do índice ${ }^{6}$.

Embora apresente nível médio de desenvolvimento humano, a cidade é marcada pela desigualdade social. O rápido crescimento demográfico, que exigiu novas políticas de atendimento à população, não produziu alternativas que incluíssem de fato os habitantes tradicionais da região - povos indígenas -, que hoje ocupam a periferia da cidade e têm acesso limitado aos bens e serviços. Boa Vista pode ser considerada uma metrópole pobre, pois mais de $50 \%$ da população vive abaixo da linha de pobreza, segundo Souza (2009, p. 67), "a renda média de um trabalhador está entre um e três salários mínimos, sendo que apenas $32,75 \%$ dos trabalhadores têm rendimento mensal superior a três salários mínimos".

Em relação às condições de trabalho da população, mais da metade da mão-de-obra de Boa Vista trabalha no setor informal, segundo Saboia e Saboia (2004), essa situação se caracteriza pela ausência de registro em carteira de trabalho e de contribuição previdenciária. São trabalhadores despossuídos de qualquer proteção trabalhista ou previdenciária e inserção no mercado é bastante precária.

O Sistema Municipal de Educação foi instituído oficialmente em 6/06/2005 (Lei $n^{\circ} 784$ ), entretanto, antes da formalização, a rede de escolas municipais já funcionava de maneira organizada, desde 1990. Em relação à estrutura e organização da carreira do magistério municipal, o primeiro estatuto da categoria data de 1992 (Lei n 282, de 10/11/1992) e, em 20/05/2009, foi estabelecido o atual PCCR.

Entre outras atribuições, a Secretaria Municipal de Educação e Cultura (SEMEC)

6 IDH-M tem metodologia de cálculo similar à do Índice de Desenvolvimento Humano (IDH), mas sua unidade de análise é o município. 0 índice pretende contribuir para a avaliação das condições de vida local, utilizando informações dos censos demográficos a respeito da educação, da saúde e da renda da população.

7 Informações coletadas em entrevista com a presidente do Sindicato dos Trabalhadores Municipais de Boa Vista (Sitram), a Sra. Sueli Moraes da Silva Cardozo, feita por telefone, em 16/11/2010. 
é responsável por propor atualizações no plano de carreira, ouvindo os profissionais da educação, em articulação com o Conselho Municipal de Educação (Lei n 784, art. 14, inciso VIII), com o intuito de assegurar o princípio da "valorização dos profissionais da educação escolar" (art. $7^{\circ}$, inciso VII).

Atualmente, a rede municipal dispõe de 72 escolas, 68 localizadas na zona urbana e quatro na zona rural. Entre elas, 43 oferecem Ensino Fundamental (EF) e 50 oferecem Educação Infantil (EI), atendendo a 12.497 crianças e jovens matriculados no EF e a 6.234 crianças na El, cobrindo respectivamente $24 \%$ e $81,5 \%$ do atendimento da cidade para essas etapas de ensino. De acordo com os dados do Censo Escolar de 2009, o Sistema emprega 1.191 docentes, dos quais 740 atuam no EF, 335 na El e 116 em outras modalidades de ensino. A rede é responsável por empregar $37,5 \%$ dos professores que trabalham até o nono ano do EF na cidade ${ }^{8}$.

Ainda segundo o Censo 2009, a rede municipal emprega 1.017 mulheres, o que corresponde a mais de $85 \%$ do total dos professores. Em termos de raça, mais de $42 \%$ dos docentes não declararam cor, e, dentre os demais, $42 \%$ consideram-se pardos, $12 \%$ brancos, $2 \%$ pretos, $1,5 \%$ indígenas e $0,2 \%$ amarelos.

No que toca à escolaridade, mais de $67 \%$ dos professores possuem nível médio completo de escolarização, com Magistério regular, Magistério indígena ou Ensino Médio, 32\% apresentam grau superior e apenas sete professores apresentam fundamental completo, entre estes, quatro trabalham na zona rural, em escolas indígenas, e três declararam-se índios. Em termos de pós-graduação, 89 docentes declaram ter especialização, o que representa apenas 7,5\% dos professores, não há mestres ou doutores na rede. Outro dado interessante é a idade dos docentes, mostrando ser a rede relativamente nova: 50\% têm até 33 anos de idade.

Os dados sobre o nível de escolarização docente são importantes, pois além de colocarem a questão da qualificação em nível superior como

8 Dados do MEC/INEP, disponíveis em http://www.ibge.gov.br/ cidadesat/link.php?uf=rr, acesso em 29/10/2010, e em http://www. inep.gov.br/bittorrent/microdados/micro_censo_escolar2009 .zip, acesso em 30/08/2010. ponto importante na pauta que deve mobilizar a política educacional de Boa Vista, evidenciam o enquadramento funcional dos professores no atual plano de carreira, que tem como base a titulação acadêmica. Conjuntamente aos dados referentes à idade, é possível fazer algumas inferências a respeito da duração da vida profissional do grupo magistério e da perspectiva que têm de alcançarem posições próximas ao topo da carreira, o que se fará no item posterior.

Com o novo PCCR, o quadro de cargos de provimento efetivo de professor da educação municipal passou a ter 2.500 vagas para Educação Básica, abrangendo o EF, a El, a Educação Especial, o primeiro segmento da Educação de Jovens e Adultos e o Ensino Fundamental Indígena, ampliando assim o número de vagas em $28 \%$ em relação à ocupação efetiva de 2009, que segundo o Censo 2009 era de 1.956 postos de trabalho.

\section{Condições de trabalho dos professores de Boa Vista: orientações do PCCR}

De acordo com o PCCR, os professores devem ministrar os dias letivos e as horas de aula estabelecidas na legislação, participar da proposta pedagógica da escola, elaborar e cumprir planos de trabalho, estabelecer estratégias de recuperação paralela, participar de períodos de planejamento e avaliação, colaborar com a administração da escola, participar de reuniões pedagógicas e iniciativas de articulação com a comunidade, buscar o aperfeiçoamento profissional e a formação continuada.

Para o desempenho dessas atividades, o professor é contratado com jornada de 25 horas semanais, das quais despende no máximo 20 horas em sala de aula, sendo o restante distribuído em atividades pedagógicas. Se por um lado essa forma de organização da jornada está vinculada à carga-horária regular dos estudantes, com 20 horas em sala de aula, por outro, permite incorporar à jornada períodos de aperfeiçoamento profissional, garantindo remuneração para tais atividades.

O estabelecimento das 25 horas de jornada e da composição do tempo de trabalho do professor é fato recente, em Boa Vista, já que no plano anterior não havia qualquer menção 
acerca dessa distribuição, além de apresentar dois tipos de jornada, atualmente extintas: de 20 e 30 horas semanais. Apesar de existirem duas jornadas, a contratação antes de 2009 dava-se fundamentalmente em regime de 30 horas e a alteração para 25 horas expressa uma conquista, na medida em que não implicou em perdas salariais.

Apesar disso, a atual jornada não segue exatamente as prescrições da Resolução $\mathrm{n}^{0}$ 2/2009 e do Parecer n 9/2009, ambos do CEB/ $\mathrm{CNE}$, que prevêem jornada preferencialmente em tempo integral, de no máximo 40 horas semanais, com incentivo à dedicação exclusiva em uma única unidade escolar como instrumento importante para a qualificação e continuidade do projeto pedagógico da instituição. As jornadas parciais induzem os docentes ao duplo emprego, entretanto, a atual jornada do município pode ser considerada como um progresso em relação à anterior, pois permite ao menos aos professores da El e dos anos iniciais do EF exercerem integralmente a docência, no caso de acumularem cargos, na própria rede ou mesmo em outras redes de ensino, fato extremamente comum em Boa Vista.

Vale destacar, contudo, que a organização da jornada que permite o acúmulo revela o processo de desvalorização salarial e de desqualificação da profissão, na medida em que gera uma sobrecarga de trabalho aos docentes. Além disso, a fixação de uma única jornada de 25 horas permite inferir que se for instituído o EF em tempo integral, não haverá contratação de professores em regime de dedicação exclusiva cumprida em um único estabelecimento escolar, mas a contratação de dois professores ou a dupla jornada de um mesmo professor.

Como o ocupante de um único cargo é impedido de exercer a docência integral em duas turmas de 20 horas-aula, que acrescidas de 10 horas-atividade totalizariam 50 horas de trabalho semanal, no caso de Boa Vista, ultrapassando o limite máximo de 40 horas do regime de dedicação exclusiva (DE), é certo que o custo de manutenção da rede se elevaria com a adoção do regime DE. Entretanto, a jornada de 40 horas viabilizaria a profissionalização do magistério, tornando a docência atividade principal e não secundária em relação a outro trabalho remunerado, contribuindo efetivamente para a garantia de uma escola pública de melhor qualidade.

Apesar da melhoria em relação à situação anterior, o plano não menciona as condições em que as atividades docentes devem acontecer, tal como a definição do número máximo de alunos por turma, aspecto essencial à garantia de boas condições de trabalho e da qualidade do processo educativo, ou mesmo a respeito das condições para a qualificação profissional, em cursos de formação inicial e continuada, e das regras que garantam uma gestão democrática, como a participação dos professores em conselhos da escola ou a forma de provimento do cargo de direção, um posto que na rede municipal de Boa Vista é preenchido em regime de comissão.

Vale lembrar ainda que, pela lei do Piso Salarial Profissional Nacional (PSPN), Lei $n^{\circ}$ $11.738 / 2008$, o tempo para a realização de atividades extraclasse deve ser de 1/3 da jornada de trabalho, o que equivaleria em Boa Vista a mais de 8 horas semanais dedicadas à formação, planejamento, trabalho coletivo etc. Infelizmente, Roraima foi um dos Estados que apoiou a Ação Direta de Inconstitucionalidade (ADIN) contra a lei do PSPN, movida pelos governadores dos Estados do Mato Grosso do Sul, Paraná, Santa Catarina, Rio Grande do Sul e Ceará, o que pode ter impactado a definição da composição da jornada na rede municipal.

Em termos de licença e afastamentos, o docente faz jus a 11 modalidades, entre elas, a permissão de afastamento para cursos de Mestrado e Doutorado, por quatro anos, e para qualificação profissional.

\section{Critérios de ingresso e movimentação na profissão}

Os docentes são considerados efetivos quando ingressam por concurso público e cumprem estágio probatório de três anos. Com o novo PCCR, a comprovação da formação em nível superior é obrigatória, desse modo, apesar de presente na atual estrutura da carreira, não é 
mais permitida a realização de concurso para o cargo de Professor de Educação Básica (PEB) cujo grau de formação é o magistério de nível médio, o que era possível até 2009.

A esse respeito, pode-se notar a intenção do legislador local de seguir o princípio contido na LDB de adotar a formação em nível superior para todos os professores da educação básica, excluindo a possibilidade de contratação de formados em nível médio, indicada na Lei, ao que parece, como possibilidade transitória (LDB/96, Art. 62 e Art. 87, § 4º). Entretanto, a ambiguidade da LDB pode contribuir para que a condição de ingresso em Boa Vista seja objetada, abrindo possibilidade para interpretações favoráveis a candidaturas de inscritos com formação de nível médio, na modalidade normal, pela compreensão de que esses candidatos estão legalmente amparados e aptos para o cargo, tornando questionável o impedimento de sua inscrição.

$O$ atual plano estrutura a carreira em cinco cargos ou classes, de acordo com a formação específica do professor, evidenciando que o posicionamento na carreira é definido pelo nível de formação docente. São eles: PEB I, com magistério médio; PEB II, com Licenciatura Plena; PEB III, com Pós-Graduação Latu Sensu; PEB IV, com Mestrado e PEB V, com Doutorado. Cada um compreende 15 níveis ( $N$ ) ou faixas salariais. Os professores concursados ingressam na carreira no cargo de PEB II, no nível inicial do cargo para o qual pleiteiam vaga ( $N$ 1).

A estrutura dos cargos vinculada à titulação parece revelar a preocupação e o incentivo da SEMEC em relação à formação de seus quadros. Entretanto, a ascensão na carreira via titulação não ocorre de forma automática, como se verá com mais detalhes adiante, mas depende de uma avaliação de desempenho do servidor. Como os cargos se diferenciam pela titulação, outro ponto que merece destaque é a dispersão entre os vencimentos básicos, em um mesmo cargo e, também, entre os diferentes cargos, para avaliar o estímulo à carreira e o incentivo à titulação.

A dispersão pode ser definida como a distância entre a menor e a maior remuneração de uma determinada categoria profissional.
Dutra Jr. et. al. (2000, p. 131), em documento publicado pelo MEC/FUNDESCOLA, com orientações aos municípios para a elaboração de planos de carreira, definem a menor remuneração como o vencimento básico, sem acréscimo de qualquer vantagem, e a maior remuneração a que corresponde ao vencimento final da carreira acrescido do máximo possível de vantagens. Afirmam ainda que:

(...) a dispersão elevada pode representar baixos níveis de remuneração inicial na carreira, o que tende a dificultar o recrutamento de profissionais qualificados. Ao contrário, dispersão reduzida, embora possibilite níveis iniciais mais altos de remuneração, pode resultar em uma carreira desestimulante, na medida em que a progressão e as vantagens acrescentem valores pecuniários insignificantes ao vencimento básico do magistério. É preciso, pois, encontrar o ponto de equilíbrio, de modo que a carreira seja atraente desde 0 seu início e que a progressão funcional e as vantagens pecuniárias representem compensação financeira satisfatória (DUTRA JR. et. al., 2000, p.131).

Considerando essa definição, mas aplicando-a inicialmente apenas ao vencimento básico, notase na tabela de vencimentos presente no PCCR (abaixo) que a distância entre o menor e o maior vencimento de um mesmo cargo é sempre de $98 \%$. Além disso, todo o professor recebe um adicional de $1 \%$ ao ano sobre o vencimento base, o que faz com que essa distância cresça quanto maior for o tempo de permanência na carreira. Se por um lado a diferença nos vencimentos base está contida nos limites estabelecidos na proposta de diretrizes para a carreira (MEC, 1995) e no Parecer n 02/1997 (CEB/CNE, 1997 não homologado pelo MEC), em que a proporção deveria ser de $50 \%$ a $100 \%$ (cf. DUTRA JR et. al., 2000, p. 132 e 133), por outro lado, se o anuênio for computado ao vencimento essa diferença ultrapassará as recomendações.

Outra ponderação possível é sobre a diferença de vencimentos entre os cargos de ingresso (PEB II N1) e de topo (PEB V N15) da carreira. Tomando apenas o vencimento base, a variação é superior a $144 \%$, proporção significativamente maior que a indicada nos documentos, mesmo sem considerar vantagens e benefícios acumulados, o que parece ser um estímulo à titulação. 
Tabela I: Vencimento base do Quadro Efetivo do Magistério Municipal

\begin{tabular}{|c|c|c|c|c|c|c|}
\hline & & $\begin{array}{l}\text { S DE VEN } \\
\text { REIRA E } \\
\text { ROFESSO } \\
\text { PREFEITU }\end{array}$ & $\begin{array}{l}\text { IMENTO } \\
\text { EMUNER } \\
\text { R PÚBLIC } \\
\text { AA MUNIC }\end{array}$ & $\begin{array}{l}\text { ÁSICO DO } \\
\text { ÇÃO DO } \\
\text { DA EDUC } \\
\text { PAL DE B }\end{array}$ & $\begin{array}{l}\text { PLANO DE } \\
\text { JADRO EFE } \\
\text { AČ̃̃O BÁSI } \\
\text { A VISTA, R }\end{array}$ & $\begin{array}{l}\text { CARGOS, } \\
\text { TIVO } \\
\text { AA DA } \\
\text { ? }\end{array}$ \\
\hline 胥 & & $\begin{array}{r}\text { Profess } \\
\text { Prefei }\end{array}$ & $\begin{array}{l}\text { r Públic } \\
\text { ura Mun }\end{array}$ & $\begin{array}{l}\text { da Educ } \\
\text { ipal de }\end{array}$ & $\begin{array}{l}\text { ção Básic } \\
\text { ja Vista - }\end{array}$ & \\
\hline $\begin{array}{l}\stackrel{0}{0} \\
\frac{\pi}{U}\end{array}$ & & 1 & ॥ & III & IV & V \\
\hline & 1 & $1.454,55$ & $1.721,38$ & $1.829,58$ & $2.013,22$ & $2.126,72$ \\
\hline & 2 & $1.527,27$ & $1.807,44$ & $1.921,05$ & $2.113,88$ & $2.233,30$ \\
\hline & 3 & $1.603,64$ & $1.897,82$ & $2.017,11$ & $2.219,57$ & $2.344,70$ \\
\hline & 4 & $1.683,82$ & $1.992,71$ & $2.117,96$ & $2.330,55$ & $2.461,94$ \\
\hline & 5 & $1.768,01$ & $2.092,34$ & $2.223,86$ & $2.447,08$ & $2.585,04$ \\
\hline & 6 & $1.856,41$ & $2.196,96$ & $2.335,05$ & $2.569,43$ & $2.714,29$ \\
\hline & 7 & $1.949,23$ & $2.306,81$ & $2.451,81$ & $2.697,90$ & $2.850,00$ \\
\hline & 8 & $2.046,69$ & $2.422,15$ & $2.574,40$ & $2.832,80$ & 2.992 .50 \\
\hline & 9 & $2.149,02$ & $2.543,26$ & $2.703,12$ & $2.974,44$ & $3.142,13$ \\
\hline & 10 & 2.256,47 & $2.670,42$ & $2.838,27$ & $3.123,16$ & $3.299,24$ \\
\hline & 11 & $2.369,30$ & $2.803,94$ & $2.980,19$ & $3.279,32$ & $3.464,20$ \\
\hline & 12 & $2.487,76$ & $2.944,14$ & $3.129,20$ & $3.443,28$ & $3.637,41$ \\
\hline & 13 & $2.612,15$ & $3.091,34$ & $3.285,66$ & $3.615,45$ & $3.819,28$ \\
\hline & 14 & $2.742,76$ & $3.245,91$ & $3.449,94$ & $3.796,22$ & $4.010,24$ \\
\hline & 15 & $2.879,90$ & $3.408,21$ & $3.622,44$ & $3.986,03$ & $4.210,75$ \\
\hline
\end{tabular}

Fonte: Lei $n^{\circ} 1145$, de 20/05/2009, anexo I.

OBS: Valores para jornada de $25 \mathrm{hs}$, vigente a partir de $09 / 2009$, com 0 enquadramento dos profissionais pelo Decreto $n^{0}$ 2.025/P, de 20/08/2009.

Com isso, nota-se que a dispersão salarial pode ser classificada como elevada, um fator de estímulo à permanência do professor na rede, na medida em que, ao progredir na carreira por tempo ou titulação, acrescenta à sua remuneração valores significativos em relação ao vencimento base inicial. Entretanto, considerando que quanto maior a diferença entre os níveis de remuneração inicial e final na carreira, maior a dificuldade do recrutamento de profissionais qualificados, podese inferir que este fato colabora para explicar os dados do Censo 2009 que mostram que 68\% dos profissionais da rede não possuem formação em nível superior. Some-se a isso o fato de que os vencimentos iniciais, que hoje não parecem baixos, começaram a vigorar apenas partir de setembro de 2009. Antes, eram significativamente inferiores: $\mathrm{R} \$ 454,55$ para PEB I N1 (valor inferior ao do salário mínimo, na época de $\mathrm{R} \$ 465,00$ ), e $\mathrm{R} \$ 721,38$ para PEB II N19 , ambos inferiores ao piso, cuja lei especificou o valor mínimo de $R \$$ 950,00 a ser pago em todo o território nacional e a ser reajustado anualmente.

Vale ressaltar que até 2006, o vencimento base dos professores era acrescido de $\mathrm{R} \$ 500,00$, a título de abono Fundef. Em 2007, os docentes negociaram com a SEMEC aumentos sucessivos do abono, para $R \$ 800,00, R \$ 900,00$ e $R \$ 1.000,00$, respectivamente em 2007, 2008 e 2009. Na elaboração do plano, a luta salarial dos professores foi pela incorporação do abono ao vencimento base, visto representar um ganho importante em função da incidência do anuênio sobre o vencimento. Tal fato se concretizou no novo PCCR, como verificado na tabela acima, expressando outra conquista da categoria.

Ao mesmo tempo, há que se analisar se a dispersão elevada pode mesmo resultar em uma carreira mais estimulante, na medida em que é preciso dispor de condições para que os profissionais cheguem ao topo, ou próximo dele, ao longo do tempo - o que será retomado mais a frente.

No que toca à movimentação ascendente na carreira, há no PCCR duas vias possíveis: a primeira é a Progressão Funcional, que se define pela passagem de um nível para outro imediatamente superior, dentro de um mesmo cargo (Lei $n^{\circ}$ 1.145/2009, art. $5^{\circ}$, inciso IX). Essa movimentação é considerada como progressão horizontal e requer interstício de dois anos para nova concessão. Considerando a Tabela I, nota-se que o aumento do valor do vencimento base entre as faixas salariais, na progressão funcional, é de $5 \%$, para qualquer cargo ou nível de formação do professor. Isso significa, na melhor das hipóteses, que após 25 anos de trabalho a professora que ocupou o mesmo cargo na rede deve estar recebendo, em termos de vencimento base, $71 \%$ a mais do que quando ingressou (estará no N 12) e, para chegar ao topo, além de continuar cumprindo todas as exigências de uma avaliação de desempenho funcional, deve permanecer por mais cinco anos na

9 Valores informados por Sueli Cardozo e presentes em reportagem do jornal eletrônico Roraima em Foco, disponível em: http://www.roraimaemfoco. com/colunistas/variedades-mainmenu-48/16730-novos-professoresmunicipais-tomam-posse-dia-30.html, acesso em 24/08/2010. 
rede. Em relação ao professor, essa diferença sobe para $88,5 \%$, pois após 30 anos de serviço alcança, na melhor das hipóteses, o nível 14, precisando de mais um ano para chegar ao topo da carreira.

Além do tempo, a progressão deve respeitar os resultados dos processos de avaliação do desempenho e observar requisitos como o exercício exclusivo na SEMEC, ausência de pena de suspensão, ausência de faltas e/ou atrasos e saídas antecipadas não justificadas, entre outros.

Em um plano de carreira, é desejável que o número de faixas salariais (ou níveis) e o interstício para promoção sejam definidos considerando a possibilidade de uma parcela significativa de docentes alcançar as etapas finais da carreira, sem, contudo, permitir que chegue ao topo muito rapidamente, tornando parte da vida funcional desestimulante. Assim, o número de faixas salariais deve ser compatível com a expectativa de duração da vida profissional do magistério, com interstícios que garantam o cumprimento, com qualidade, dos requisitos exigidos para a ascensão profissional. Vale lembrar que a aposentadoria voluntária pode ser requerida pelos professores após 30 anos de serviços e 55 de idade, pelas professoras e após 25 anos de serviço e 50 de idade, que a aposentadoria compulsória dá-se aos 70 anos de idade.

Considerando que cada cargo da rede apresenta 15 faixas salariais e que o interstício para a progressão entre as faixas é de dois anos, aliado à avaliação de desempenho e ao estágio probatório de três anos, ou seja, na melhor das hipóteses o professor consegue chegar ao topo da carreira após 31 anos de magistério, tem-se que, apesar de longa e de depender de procedimentos de avaliação de desempenho, a amplitude da carreira deve permitir a uma parcela significativa de docentes chegarem próxima ao final da carreira, visto que os professores municipais são relativamente jovens (50\% têm até 33 anos de idade) e podem permanecer trabalhando para além do tempo e da idade referente à aposentadoria voluntária.

O segundo tipo de movimentação é chamado de Promoção por Titulação e se define pela passagem de uma classe (ou cargo) para outra imediatamente superior, de acordo com a titulação acadêmica do servidor (Lei n ${ }^{\circ}$ 1.145/2009, art. $5^{\circ}$, inciso X). Tomando os dados da Tabela I, nota-se que são diferentes as proporções de aumento do vencimento base entre os diversos cargos de professor na rede: de PEB I para II, a diferença é de mais de $18 \%$, a mais acentuada entre os cargos, entretanto inferior ao teto estipulado pela Resolução n $03 / 97$ (art. $6^{\circ}, \mathrm{V}$ ), que dispõe que a remuneração dos docentes com licenciatura plena não deva ultrapassar em mais de $50 \%$ a dos formados em nível médio. A diferença no vencimento base de PEB II para III diminui, é de cerca de $6 \%$; a de PEB III para IV sobe, é de 10\% e, finalmente, a de PEB IV para $V$ é a menor diferença, com pouco mais de $5 \%$.

Essa movimentação é considerada vertical e, além de comprovar a titulação, o servidor deve apresentar resultados satisfatórios na avaliação de desempenho funcional e ter cumprido estágio probatório. Outra observação pertinente a essa questão, é a de que para além dos cursos de pósgraduação que permitem a mudança de cargo e melhor remuneração, não está previsto no PCCR qualquer tipo de ascensão na carreira aos docentes que realizam atividades de formação continuada em cursos de aperfeiçoamento e atualização profissional, por exemplo, deixando a modalidade de formação não acadêmica sem incentivo financeiro.

Uma das pautas que mobilizou os professores quando da elaboração do plano de carreira, segundo a presidente do Sitram, foi à possibilidade de obter vantagens salariais considerando as atividades e cursos de formação não acadêmicos cujas cargas horárias somassem o mesmo número de horas de cursos de pós-graduação, entretanto esse pleito não foi acatado pela SEMEC. Apesar disso, a presidente afirma que a Secretaria vem investindo na formação inicial e continuada de seus quadros, buscando parcerias, principalmente com a Universidade Federal de Roraima e com o Instituto Federal de Educação, Ciência e Tecnologia de Roraima. Outra conquista ressaltada, em relação ao plano de 2003, referese ao fim da imposição de um quantitativo de vagas para efetivar a movimentação funcional. Atualmente, basta ao professor apresentar seu título e cumprir os requisitos da avaliação de desempenho para ascender na carreira.

Neste contexto, ambas as formas de ascensão estão permeadas por processos de avaliação do desempenho e, de acordo com 
Sueli Cardozo, tal vínculo foi imposto pela SEMEC que abriu, entretanto, negociação para definir os procedimentos e o percentual de pontuação necessário à aprovação dos docentes. Essa imposição está em consonância com as prescrições da LDB/96, que prevê "progressão funcional baseada na titulação ou habilitação e na avaliação de desempenho" (art. 67, inciso IV).

Em Boa Vista, concluído o estágio probatório, o profissional do magistério fica habilitado à primeira Progressão Funcional e a qualquer Promoção por Titulação. Para a avaliação de seu desempenho deve ser constituída uma subcomissão temporária de avaliação na escola, composta pelo diretor, um professor e o próprio servidor avaliado. Além da auto-avaliação, realizada pelo docente, são utilizados diferentes instrumentos, como as avaliações dos membros da subcomissão e a cópia daficha funcional. Em cada escola ficam arquivados os portfólios dos professores, preenchidos pela subcomissão, no qual são registrados os apontamentos avaliativos, a responsabilidade por esses registros é da gestão escolar.

Para regulamentar esse processo, estão definidos critérios subjetivos e objetivos de avaliação (cf. Decreto n. ${ }^{\circ} 218 / E$, de 23/12/2009). Há quatro eixos que balizam os critérios subjetivos: Criatividade, em que se considera a capacidade para inovar em relação às práticas didáticas e pedagógicas; Participação efetiva nas atividades pedagógicas, que considera a capacidade de desenvolver atividades em equipe, mantendo postura profissional participativa e colaborativa; Relacionamento de respeito com os demais profissionais e alunos, que afere o comportamento em termos de lisura, respeito e solidariedade e Dinâmica, competência e prática inovadora na atividade profissional, que observa a capacidade criativa na elaboração e execução de projetos pedagógicos e metodologia que resultem na melhoria e qualidade da aprendizagem.

Como a própria adjetivação dos critérios evidencia, a subjetividade dessa etapa de avaliação do desempenho pode dar margem a apreciações imparciais e tendenciosas, por parte dos membros da subcomissão, devido à dificuldade de se mensurar, por exemplo, o que é, e o quanto de criatividade docente pode proporcionar de fato impactos positivos na promoção de mais qualidade na relação ensinoaprendizado. Ademais, a valorização profissional assentada em características pessoais contradita a própria natureza do cargo público e as condutas que devem caracterizá-lo, como a observância de normas previamente estabelecidas e a não submissão à vontade pessoal de superiores. Nesse sentido, parece que os itens subjetivos de avaliação contribuem para a elevação do risco de tornar esse processo um instrumento de controle do trabalho do professor e não de valorização da profissão. É um tipo de tratamento e de relação funcional que evidencia como tendência a incorporação de traços característicos da administração pública de tipo gerencial, ao valorizar servidores que adotam comportamentos e valores próximos daqueles esperados no setor privado (PEREIRA, 1996).

No que toca aos oito parâmetros referentes aos critérios objetivos, tem-se a seguinte pauta de avaliação: Assiduidade e pontualidade, que exige comparecimento ao serviço e desempenho das funções; Disciplina, em que são aferidos o cumprimento de ordens e normas, cooperação e participaçãoemtrabalhosdeequipeereceptividade às críticas; Capacidade de iniciativa, em que se avalia a criatividade, espontaneidade, interesse, capacidade de tomar decisões, facilidade na resolução de problemas e contribuição pela experiência profissional; Responsabilidade, medida pelo comprometimento, amadurecimento profissional, dedicação, confiança, agilidade e zelo; Qualidade, em que se consideram a dinamicidade e o apuro nos trabalhos didáticos, paradidáticos e gerenciais; Ética profissional, aferindo a consciência de que o trabalho é regido por princípios éticos materializados na adequada prestação dos serviços públicos, na conduta moral, dignidade, decoro, zelo, eficácia e consciência dos princípios morais no exercício do cargo; Conhecimento profissional, em que se considera o grau de competência, conhecimento, técnicas didáticas e pedagógicas e Atendimento, aferindo o grau de interesse e disponibilidade para prestar atendimento aos alunos durante e após as aulas e aos pais dos estudantes.

Mesmo nos itens qualificados como objetivos é possível notar a carga de subjetividade e a dificuldade de se estabelecer parâmetros para a mensuração 
de tais características. Ambos os instrumentos de avaliação parecem precários e pouco precisos para aferir o desempenho profissional e, a depender do contexto em que venham a ser aplicados, podem ganhar um caráter persecutório ou consistir em mera formalidade, pouco contribuindo para a definição do mérito profissional ou da melhoria da educação.

Há vários obstáculos em se atrelar o incremento da remuneração do professor à avaliação de seu desempenho, tal como a dificuldade de precisar o que é o desempenho docente e de identificar como esse desempenho afeta a qualidade educacional e o aprendizado. Nesse sentido, Morduchowicz (2003, p. 23) alerta para o fato "de que o trabalho realizado pelos docentes, além de ter múltiplos objetivos, é um serviço cujos resultados são intangíveis, difíceis de quantificar e medir". Não se trata, aqui, de negar a necessidade de avaliar e objetivar o avanço do trabalho docente, mas de se considerar o real benefício de atrelar o resultado desse processo à definição de acréscimos salariais e à ascensão na carreira.

A avaliação docente em Boa Vista é composta também pelos seguintes indicadores educacionais: Taxa de Rendimento Escolar, definida pela porcentagem igual ou superior a $70 \%$ de alunos que avançam nos processos de aprendizagem, no $2^{\circ} \mathrm{e}$ $4^{\circ}$ bimestres, e Taxa de Reprovação Escolar. Apesar das taxas de rendimento e reprovação serem parâmetros empiricamente observáveis, é preciso ponderar que o fato de estarem incorporadas à avaliação de desempenho, e esta, por sua vez, incidir sobre a ascensão salarial, pode estimular os docentes a atuarem na avaliação de seus alunos de forma enviesada, objetivando benefícios pessoais.

Cabe à SEMEC orientar, supervisionar e coordenar os processos de avaliação de desempenho dos profissionais do magistério, bem como realizar inspeções e fiscalizar o cumprimento da legislação pertinente às avaliações. A concessão da Progressão Funcional ou da Promoção por Titulação depende do relatório de avaliação expedido pela referida comissão, submetido à autoridade da SEMEC.

Pode-se observar que o PCCR atribui bastante valor à avaliação do desempenho ao vincular as duas formas de movimentação na carreira. Entretanto, se não houver investimento da Secretaria na formação inicial e continuada de seu corpo docente, ficará a cargo dos próprios professores a responsabilidade e as iniciativas de melhoria e superação de suas dificuldades. Além disso, a aferição do desempenho funcional promove uma cultura de avaliação que se não estiver assentada em processos transparentes e objetivos, deve prejudicar ao invés de colaborar com o desenvolvimento profissional dos servidores, com a melhoria da qualidade de ensino e com a valorização do magistério.

\section{Considerações Finais}

O PCCR de Boa Vista é um instrumento que permite ao professor divisar a trajetória como profissional do magistério e algumas das relações e condições de trabalho presentes no Sistema Municipal de Educação. Após a aprovação em concurso público e um período probatório de três anos, o docente adquire estabilidade e pode ascender de duas formas na carreira, via titulação e via tempo de serviço, ambas aliadas a uma avaliação de desempenho funcional. Aestabilidade e a movimentação interna caracterizam o regime de trabalho burocrático clássico das administrações públicas profissionais, o que pode estimular os jovens à carreira docente, visto que o universo atual de relações sociais e de trabalho está num crescente inseguro e precário.

Entretanto, as características presentes na avaliação de desempenho funcional de Boa Vista agregam a esse modelo burocrático traços da administração pública de tipo gerencial, em que se estabelece um controle por resultados, a posteriori, ao invés de normas rígidas, com controle sistemático dos processos administrativos e de trabalho - uma mudança que tende a promover situações instáveis e incertas de trabalho.

A qualidade do desempenho docente tem sido determinada, em Boa Vista, por uma série de elementos, alguns deles objetivos, ainda que problemáticos, tais como as taxas de fluxo escolar, informações sobre a pontualidade e a assiduidade docente, a observância de normas, mas também por ideais subjetivos de mérito pessoal e de performances individuais, que não permitem aos profissionais o conhecimento objetivo dos critérios que fundamentam o êxito ou o fracasso 
de sua atuação. O uso de elementos subjetivos para a autocrítica pode levar o professor a perder tanto o referencial identitário da profissão quanto a compreensão da complexidade de seu ofício, ficando à mercê da incerteza, dominado pelo receio de ser coagido, censurado e repreendido, além de estar sob constante pressão.

Essa forma de controle do trabalho docente não está apenas mediada pelas relações de poder autoritárias e hierárquicas, mas tem instigado também a intensificação do trabalho, ao requisitar dos professores maior participação e compromisso no cotidiano escolar, sem, contudo, possibilitar um regime de dedicação exclusiva, o que vem permitindo - para não dizer estimulando - a dupla jornada de trabalho. Essa situação, aliada à cultura do desempenho individual, pode levar o docente ao estresse e ao sofrimento em sua atividade profissional.

Outros fatores que poderiam desestimular os pretendentes à carreira docente são: a ausência de reconhecimento de atividades não acadêmicas à ascensão profissional, fazendo da exigência de formação superior no ingresso a principal estratégia de profissionalização do quadro docente de Boa Vista, além da classificação funcional de ingresso (PEB II, N1) que só considera a titulação em nível de pós-graduação depois do período probatório, a despeito da carreira estar estruturada na titulação.
Entretanto, há fatores concretos no PCCR que estimulam novos quadros, tais como a possibilidade de os profissionais alcançarem as etapas finais da carreira; a dispersão salarial elevada, que permite acréscimos significativos ao vencimento base, ao longo da carreira, com as progressões e promoções funcionais; a possibilidade de afastamento para a formação acadêmica, sem prejuízo para o funcionário, o que significa adicionais expressivos ao vencimento base; a incorporação do abono do Fundeb ao vencimento base, sobre o qual incide o anuênio, ea ausência de quantitativo de vagas à concretização de qualquer movimento ascendente na carreira.

Além disso, é preciso considerar que além de pertencerem ao mercado de trabalho formal em uma cidade onde tal condição é inexistente para mais de metade da população, os professores boa-vistenses apresentam remuneração superior a três salários mínimos, com uma jornada de 25 horas de trabalho semanal, fazendo parte, portanto, do terço da população que apresenta maior rendimento na cidade. Considerando ainda que boa parte desses profissionais tem dupla jornada de trabalho, a situação salarial e trabalhista do magistério deve sem dúvida constituir-se como fator de estímulo e atratividade para os futuros postulantes à carreira docente no município de Boa Vista.

\section{Referências Bibliográficas}

BRASIL. Lei no 11.494, de 20/07/07 Lei $n^{\circ} 11.738$, de 16/07/08 . Lei $n^{\circ}$ 9.394, de 20/12/96 . Lei no 9424, de 24/12/96

BOA VISTA. Lei n 714, de 10/12/2003. Diário Oficial do Município, Poder Executivo. Lei no 1.145, de 20/05/2009. Diário Oficial do Município, Poder Executivo. Lei n ${ }^{\circ}$ 784, de 06/06/2005. Diário Oficial do Município, Poder Executivo. . Decreto n 218/E, de 23/12/2009. Diário Oficial do Município, Poder Executivo.

CNE/CEB. Parecer n 2, de 26/02/1997. Diretrizes para os Novos Planos de Carreira e de Remuneração do Magistério dos Estados, do Distrito Federal e dos Municípios. Não homologado pelo MEC. 